\title{
Studying Relationship Between Static and Dynamic Balance Indices and Knee Pain Severity in Patients with Knee Osteoarthritis
}

\author{
Narges Jahantigh Akbari ${ }^{1}$, Ahmad Reza Askary Ashtiani ${ }^{2}$, Mehdi Mohammadi ${ }^{3}$ \& Salman Nouraisarjou ${ }^{4}$ \\ ${ }^{1}$ Master of Physiotherapy, Student Research Committee, Health Promotion Research Center, Zahedan University \\ of Medical Sciences, Zahedan, Iran \\ ${ }^{2}$ Assistant Professor of Physiotherapy, Health Promotion Research Center, Zahedan University of Medical \\ Sciences, Zahedan, Iran \\ ${ }^{3}$ Associate Professor in Epidemiology Department, Health Promotion Research Center, Zahedan University of \\ Medical Sciences, Zahedan, Iran \\ ${ }^{4}$ Msc of physiotherapy, Bimeh Salamat Saravan, Saravan, Iran \\ Correspondence: Ahmad Reza Askary Ashtiani, Health Promotion Research Center, Zahedan University of \\ Medical Sciences, Zahedan, Iran. E-mail: Ahmadaskary@gmail.com
}

Received: June 5, 2017

Accepted: June 23, 2018

Online Published: July 19, 2018

doi:10.5539/jmbr.v8n1p80

URL: https://doi.org/10.5539/jmbr.v8n1p80

\begin{abstract}
Background and Objectives: One of the predisposing factors for postural sway changes in patients with knee osteoarthritis is the severity of knee pain. Therefore, the purpose of this study was to evaluate the relationship between pain severity and static and dynamic balance indices in patients with knee osteoarthritis.
\end{abstract}

Materials and Methods: 15 patients with knee osteoarthritis were selected through simple non-probability sampling. Static and dynamic balance indices were also measured by Biodex system, the pain severity by the Visual Analogue Scale (VAS) in two pre and post time intervals. The treatment was performed for the balance trainings group for 3 weeks and 5 times per week. Paired statistical t-test and Pearson test were used to analyze the data.

Results: The results showed that balance trainings resulted in significant improvement in pain severity and dynamic and static balance indices. There was a significant direct correlation between pain severity and anterior-posterior stability index and medial-lateral stability index on two feet with the closed eyes with exercise, respectively (rho $=0.52, \mathrm{p}=0.04)$ and $(\mathrm{rho}=0.53, \mathrm{p}=0.03)$. There was also a significant indirect correlation between pain severity and anterior-posterior stability index on the affected leg with the closed eyes $($ rho $=0.60, p=0.01)$.

Conclusion: The results of the study confirm the direct and indirect relationship between dynamic balance indices and pain intensity; in the future studies the effect of pain on neuromuscular factors should be considered.

\section{Introduction}

Osteoarthritis is the most common articular disease in the world and is considered as a major factor of disability(Moskowitz, 1992; Shakoor, Furmanov, Nelson, Li, \& Block, 2008). The majority of people aged 40 years have radiographic evidence of knee osteoarthritis, and the incidence of this disease increases with age (Moskowitz, 1992). Knee osteoarthritis has been known as one of the most important causes of pain, disability and reduced balance and low quality of life (Masui et al., 2006). It causes many social, economic, and psychological problems to a person (Lyytinen et al., 2010). Osteoarthritis is a disease destructing synovial joint that affects articular cartilage, leading to cartilage destruction and changes in other tissues, including synovial membrane inflammation, muscle weakness, and new bone formation (Peat, McCarney, \& Croft, 2001). In patients with knee osteoarthritis, the knee pain is a major pathologic difficult that may reduce muscle strength (Kim, Lee, \& Lim, 2016). Although there is a relationship between knee osteoarthritis and physical function, association with knee pain is significantly stronger (Odding et al., 1998).

Pain may be a factor affecting muscle strength appraisal and precision of proprioception (Hassan, Doherty, Mockett, \& Doherty, 2002). The pain origin has remained unclear, so the association of pain with other important physiological variables requires examination (Hassan et al., 2002). Pain may damage any motor part (movement, 
strength and activity) or sensory part (proprioception, balance) of muscular performance (Hassan et al., 2002). Balance control is essential for everyday life (Hassan, Mockett, \& Doherty, 2001). The postural control is complex; it includes the afferent paths, central processing, and the precise use of motor units (Hassan et al., 2001). Individuals with knee osteoarthritis have been shown to have a disturbed proprioception as compared to control individuals of the same age (Barrett, Cobb, \& Bentley, 1991). On the other hand, according to the report, there is an inconsistent relationship between pain and severity of radiographic symptoms of knee osteoarthritis (Hassan et al., 2001). Treatment through balance trainings in the rehabilitation process may reduce pain and remove functional limitations following pain.

Many treatments have been suggested to increase the balance in patients with knee osteoarthritis (Lyytinen et al., 2010). It has been reported in many studies that balance is necessary to prevent falls in people with knee osteoarthritis. Therefore, a suitable treatment plan for improving balance is prioritized (Duman, Taskaynatan, Mohur, \& Tan, 2012). In a study conducted by N. Shakoor et al, it has been reported that pain is indirectly related to muscle strength and proprioception, so that a change in the mean pain through 8 weeks of home trainings can cause changes in muscle strength and proprioception (Shakoor et al., 2008). In a study done by Kanda Chaipinyo et al, they examined the effect of home trainings on balance and home trainings on strength in patients with knee osteoarthritis, both of which resulted in improved pain (Chaipinyo \& Karoonsupcharoen, 2009). In a study done by MC Hall et al, they examined the relative effect of knee radiographic osteoarthritis on pain, quadriceps muscle strength, proprioception and static postural sway and lower limb function; they came to the conclusion that patients with knee pain had less power of quadriceps muscle, a greater postural fluctuation and more disability than individuals suffering from radiographic osteoarthritis. On the other hand, individuals with radiographic osteoarthritis had less ability in quadriceps muscle and more disability than normal people, but no different postural sway was found (Hall, Mockett, \& Doherty, 2006). In a study conducted by Kyung Kim et al, they examined the effect of strengthening and balance trainings in knee osteoarthritis patients and the correlation between increased balance and pain (Kim et al., 2016).

Knee pain is an important sign of knee osteoarthritis and the severity of knee pain is a major determinant of disability (Davis, Ettinger, Neuhaus, \& Mallon, 1991). The origin of pain has remained unclear, so the association of pain with other important physiological variables requires examination (Hassan et al., 2002). Since there has been no study to determine the relationship between pain severity and balance indices in knee osteoarthritis patients after balance trainings, the aim of this study was to determine the relationship between static and dynamic balance indices and pain severity in patients with knee osteoarthritis following balance trainings.

\section{Materials and Methods}

Study design: Our descriptive-analytic study was carried out in Zahedan University of Medical Sciences in 2016. 15 knee osteoarthritis patients were initially evaluated for pain severity and postural stability indices and then treated for 3 weeks and 5 times per week (Perlau, Frank, \& Fick, 1995) for balance trainings and after treatment they were re-evaluated.

Population under study and patients screening: For this study, 15 patients with knee osteoarthritis were selected through simple and convenient sampling. The criteria for participation in the study are as follows: Men and women with chronic knee pain for at least 3 months (Ezadpanah, Moazami, \& Khoshraftar Yazdi, 2016), age of 46 to 72 years (Rätsepsoo et al., 2013), knee osteoarthritis confirmation based on clinical symptoms, morning stiffness usually being removed after 30 minutes (Chaipinyo \& Karoonsupcharoen, 2009), lack of history of trauma (Ezadpanah et al., 2016), injury or surgery, and lower limb fracture. Exclusion criteria include: a history of cardiovascular disease (Chaipinyo \& Karoonsupcharoen, 2009), Parkinson's disease, physiotherapy intervention for their knees during the past 6 months, disturbance in the vestibular system (Chaipinyo \& Karoonsupcharoen, 2009). Patients were participated in the study after reading and signing a written informed testimonial. This study was approved by the Scientific Committee of the Rehabilitation Group and the Moral Committee of Zahedan University of Medical Sciences.

Data collection: meter with precision of centimeter was used to measure people's height, digital scales for measuring body weight (for calculating body mass index), and Biodex Balance System for measuring balance indices and Visual Analogue Scale (VAS) questionnaire was used for Measurement of pain severity.

Evaluation of Balance Indices: Overall, anterior-posterior and lateral stability indices were measured by the Biodex Balance System (New York, Biodex Medical System, Inc., SW 45-30D-E6N SD 950-304USA). In the Biodex balance system, the least stable condition was related to 1 and the most stable condition was 12 . Index of overall stability is the displacement variance of the device plate in terms of degree to the horizontal, anterior-posterior stability index is the displacement variance of the device plate in terms of degree relative to the horizon for the 
movements of the sagittal surface, and the lateral stability index the device's plate displacement variance in terms of degree to the horizontal level for frontal surface movements. The degree of deviation from the center represented individual's score, lower score indicating less deviation and greater balance. For performing a test of 4 positions of standing on 2 limbs with open and closed eyes, standing on the affected limb with open and closed eyes, the individual conducted static and dynamic balance tests. In the static state, the plate must be placed fixed and without moving. To check the dynamic balance, the hardness of force plate must be adjusted on 8 from the beginning to the end of the movement. The patient, keeping in mind the release time of the force plate, should maintain the cursor in the middle of the small circle, divided into 4 parts. By performing the main test, in form of three repetitions, the results of postural stability were presented as a overall, anterior-posterior, and lateral index in a table (Akbari, Ashtiani, \& Mohammadi).

Pain severity evaluation: In this study, the Visual Analogue Scale (VAS) was used to measure the severity of pain. So a set of descriptive expressions was put in place and the patient was asked to score his/her pain severity according to a graded ruler graded through 0 (no pain) to 10 (most severe pain) (Ashtiani, Akbari, Mohammadi, \& Nouraisarjou, 2018). VAS was found to be reliable and valid for measuring the pain severity (Jan, Lin, Lin, Lin, \& Lin, 2009; Messier et al., 2000).

\subsection{Balance Trainings}

The trainings lasted for 3 weeks, 5 sessions per week and 15 sessions (Duman et al., 2012), and each session for approximately 20 minutes; during each training the individual rested enough. This research project was carried out at the Physiotherapy Clinic of Razmjou Moqaddam of Zahedan University of Medical Sciences.

\section{Warm up trainings:}

These trainings are performed for 10 minutes before the trainings begin and include the following ones: 1) slow walk for 5 minutes, stretching trainings including 2) the patient is in a supine position and the knees are extended in this position with his right hand towards the Left of the body and hold it for 10 seconds and then does it with the other hand. 3. The patient is placed in the supine position and takes his knees with one or both legs toward the chest. 4) $\mathrm{He} / \mathrm{she}$ performs stretching movements of the hamstring muscles. 5) He/she performs stretching movements of the thigh joint muscles. 6) He/she performs stretching movements of muscles behind the shin.

Standing on one leg: The person was asked to stand on one leg, while standing close to a support or desk, and the other leg was raised and kneeling bent. Then the balance of the person was measured by standing on one leg (Kavounoudias, Gilhodes, Roll, \& Roll, 1999). Every time a person could not maintain his balance, he stood on 2 legs a few seconds, then stood on the other leg, and this training was repeated with this process, for 2 minutes (McCarthy et al., 2004).

Stepping forward and backward then towards two sides 30 reps for each leg. Patients along with this training performed 30 repetitions of the mini squat of two sides with a flexion angle of $15-30^{\circ}$ of knee in the painless range to strengthen the quadriceps muscle in a standing position; the components of this balance training were as follows:

1) Stepping forward and backward with the left leg (30 repetitions)

2) 2 sided mini squat (10 times)

3) Stepping forward and backward with the right leg (30 times)

4) 2 sided mini squat (10 times)

5) Stepping lateral to the left (30 times)

6) 2 sided mini squat (10 times)

7) Stepping lateral to the right (30 times).

Determination of sample size: Considering previous studies, 15 patients with knee osteoarthritis were considered for study.

Statistical analysis: for intra-group comparison the statistical paired T-test and Pearson test were used to evaluate correlation. The significance level was considered less than five percent.

\section{Results}

The results of the descriptive test and the study of the mean age, weight, height, and BMI in the balance trainings group have been presented in Table 1. Referring to previous studies, the sample size was estimated to be 15 people for the Balanced Trainings Group. 
Table 1. Demographic characteristics of participants

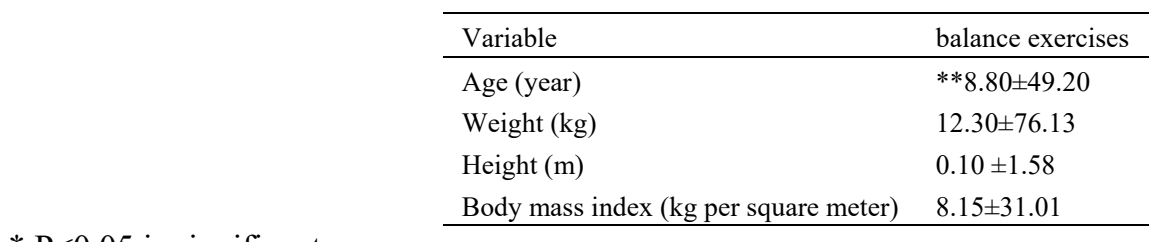

* $\mathrm{P}<0.05$ is significant

Body mass index (kg per square meter) $\quad 8.15 \pm 31.0$

** Data were stated in the form of $\mathrm{SD} \pm$ mean

Mean and standard deviation of pain severity and data related to overall, anterior-posterior and lateral stability indices in standing on two legs and affected leg in static and dynamic position with open and closed eyes and comparing the results of post-treatment with pre-treatment and value $P$ related to the comparison of the results of post-treatment with pre-treatment and the relationship between these balance indices and the severity of pain and the value $P$ related to them have been given in Tables 2 and 3.

Table 2. Relationship between static stability indices and pain severity before and after balance training and comparing mean of data before and after treatment

\begin{tabular}{llllllll}
\hline \multirow{2}{*}{ Variable } & \multicolumn{3}{c}{ Before intervention } & \multicolumn{3}{c}{ After intervention } & Comparing the results after intervention \\
\cline { 2 - 8 } & Mean \pm SD & Pearson & P value & Mean \pm SD & Pearson & P value & P value \\
\hline SMOSIBEO & $0.74 \pm 0.42$ & -0.18 & 0.51 & $0.52 \pm 0.17$ & -0.31 & 0.25 & $0.02^{*}$ \\
SMOSIBEC & $2.60 \pm 1.60$ & -0.17 & 0.52 & $1.64 \pm 0.71$ & -0.21 & 0.43 & 0.12 \\
SMAPIBEO & $0.57 \pm 0.39$ & -0.19 & 0.48 & $0.36 \pm 0.12$ & -0.29 & 0.29 & $0.04^{*}$ \\
SMAPIBEC & $2.14 \pm 1.71$ & -0.24 & 0.37 & $1.23 \pm 0.70$ & 0.01 & 0.96 & 0.16 \\
SMMLIBEO & $0.31 \pm 0.12$ & -0.05 & 0.83 & $0.30 \pm 0.13$ & 0.09 & 0.73 & 0.80 \\
SMMLIBEC & $1.03 \pm 0.47$ & 0.23 & 0.39 & $0.80 \pm 0.43$ & 0.05 & 0.86 & 0.05 \\
SMOSIUSIEO & $8.74 \pm 3.15$ & 0.00 & 0.99 & $7.83 \pm 2.81$ & -0.27 & 0.31 & 0.10 \\
SMOSIUSIEC & $9.57 \pm 3.15$ & 0.08 & 0.76 & $7.97 \pm 2.85$ & -0.25 & 0.36 & $0.00^{*}$ \\
SMAPIUSIEO & $2.90 \pm 2.05$ & -0.36 & 0.18 & $2.12 \pm 1.69$ & 0.07 & 0.79 & 0.33 \\
SMAPIUSIEC & $3.75 \pm 2.11$ & -0.29 & 0.29 & $2.77 \pm 1.42$ & 0.14 & 0.60 & 0.06 \\
SMMLIUSIEO & $7.94 \pm 3.07$ & 0.11 & 0.68 & $7.26 \pm 2.78$ & -0.34 & 0.20 & $0.00^{*}$ \\
SMMLIUSIEC & $8.42 \pm 3.10$ & 0.19 & 0.48 & $7.16 \pm 2.95$ & -0.31 & 0.24 & $0.01^{*}$ \\
Pain & $6.53 \pm 2.32$ & 1 & & $4.60 \pm 1.91$ & 1 & & $0.00^{*}$ \\
\hline
\end{tabular}

** Data were stated in the form of $\mathrm{SD} \pm$ mean, $* \mathrm{P}<0.05$ is significant

SMOSIBEO: STATIC MEAN OVERAL STABILITY INDEX BILATERAL EYES OPEN

SMOSIBEC: STATIC MEAN OVERAL STABILITY INDEX BILATERAL EYES CLOSE

SMAPIBEO:STATIC MEAN ANTERIOR POSTERIOR INDEX BILATERAL EYES OPEN

SMAPIBEC: STATIC MEAN ANTERIOR POSTERIOR INDEX BILATERAL EYES CLOSE

SMMLIBEO: STATIC MEAN MEDIAL LATERAL INDEX BILATERAL EYES OPEN

SMMLIBEC: STATIC MEAN MEDIAL LATERAL INDEX BILATERAL EYES CLOSE

SMOSIUSIEO: STATIC MEAN OVERAL STABILITY INDEX UNILATERAL STANCE INVOLVED EYES OPEN

SMOSIUSIEC: STATIC MEAN OVERAL STABILITY INDEX UNILATERAL STANCE INVOLVED EYES CLOSE

SMAPIUSIEO: STATIC MEAN ANTERIOR POSTERIOR INDEX UNILATERAL STANCE INVOLVED EYES OPEN

SMAPIUSIEC: STATIC MEAN ANTERIOR POSTERIOR INDEX UNILATERAL STANCE INVOLVED EYES CLOSE

SMMLIUSIEO: STATIC MEAN MEDIAL LATERAL INDEX UNILATERAL STANCE INVOLVED EYES OPEN

SMMLIUSIEC: STATIC MEAN MEDIAL LATERAL INDEX UNILATERAL STANCE INVOLVED EYES CLOSE 
Table 3. Relationship between dynamic stability indices and pain severity before and after balance training and comparing mean of data before and after treatment

\begin{tabular}{llllllll}
\hline \multirow{2}{*}{ Variable } & \multicolumn{3}{c}{ Before intervention } & \multicolumn{3}{c}{ After intervention } & Comparing the results after intervention \\
\cline { 2 - 7 } & Mean \pm SD & Pearson & P value & Mean \pm SD & Pearson & P value & P value \\
\hline DMOSIBEO & $2.85 \pm 1.86$ & 0.28 & 0.30 & $1.56 \pm 0.89$ & 0.49 & 0.06 & $0.00^{*}$ \\
DMOSIBEC & $5.83 \pm 2.86$ & 0.27 & 0.31 & $3.04 \pm 1.18$ & 0.26 & 0.33 & $0.00^{*}$ \\
DMAPIBEO & $2.28 \pm 1.84$ & 0.17 & 0.53 & $1.27 \pm 1.18$ & 0.42 & 0.11 & $0.00^{*}$ \\
DMAPIBEC & $4.41 \pm 2.90$ & 0.29 & 0.28 & $2.18 \pm 0.92$ & 0.52 & $0.04^{*}$ & $0.00^{*}$ \\
DMMLIBEO & $1.20 \pm 0.60$ & 0.40 & 0.13 & $0.73 \pm 0.24$ & 0.27 & 0.32 & $0.00^{*}$ \\
DMMLIBEC & $2.84 \pm 1.06$ & 0.44 & 0.09 & $1.66 \pm 0.81$ & 0.53 & $0.03^{*}$ & $0.00^{*}$ \\
DMOSIUSIEO & $13.70 \pm 4.92$ & -0.00 & 0.99 & $10.83 \pm 5.06$ & -0.17 & 0.53 & $0.00^{*}$ \\
DMOSIUSIEC & $13.84 \pm 4.73$ & -0.19 & 0.49 & $11.50 \pm 5.30$ & -0.35 & 0.20 & $0.02^{*}$ \\
DMAPIUSIEO & $3.60 \pm 2.14$ & 0.30 & 0.27 & $2.34 \pm 1.42$ & -0.00 & 0.98 & $0.02^{*}$ \\
DMAPIUSIEC & $4.52 \pm 1.60$ & -0.47 & 0.73 & $2.50 \pm 1.44$ & -0.60 & $0.01^{*}$ & $0.00^{*}$ \\
DMMLIUSIEO & $12.81 \pm 4.73$ & -0.08 & 0.77 & $10.34 \pm 5.06$ & -0.18 & 0.50 & $0.02^{*}$ \\
DMMLIUSIEC & $12.67 \pm 4.86$ & -0.13 & 0.62 & $10.90 \pm 5.36$ & -0.21 & 0.44 & 0.06 \\
pain & $6.53 \pm 2.32$ & 1 & & $4.60 \pm 1.91$ & 1 & & $0.00^{*}$ \\
\hline
\end{tabular}

** Data were stated in the form of $\mathrm{SD} \pm$ mean

* $\mathrm{P}<0.05$ is significant

DMOSIBEO: DYNAMIC MEAN OVERAL STABILITY INDEX BILATERAL EYES OPEN

DMOSIBEC: DYNAMIC MEAN OVERAL STABILITY INDEX BILATERAL EYES CLOSE

DMAPIBEO: DYNAMIC MEAN ANTERIOR POSTERIOR INDEX BILATERAL EYES OPEN

DMAPIBEC: DYNAMIC MEAN ANTERIOR POSTERIOR INDEX BILATERAL EYES CLOSE

DMMLIBEO: DYNAMIC MEAN MEDIAL LATERAL INDEX BILATERAL EYES OPEN

DMMLIBEC: DYNAMIC MEAN MEDIAL LATERAL INDEX BILATERAL EYES CLOSE

DMOSIUSIEO: DYNAMIC MEAN OVERAL STABILITY INDEX UNILATERAL STANCE INVOLVED EYES OPEN

DMOSIUSIEC: DYNAMIC MEAN OVERAL STABILITY INDEX UNILATERAL STANCE INVOLVED EYES CLOSE

DMAPIUSIEO: DYNAMIC MEAN ANTERIOR POSTERIOR INDEX UNILATERAL STANCE INVOLVED EYES OPEN

DMAPIUSIEC: DYNAMIC MEAN ANTERIOR POSTERIOR INDEX UNILATERAL STANCE INVOLVED EYES CLOSE

\section{DMMLIUSIEO: DYNAMIC MEAN MEDIAL LATERAL INDEX UNILATERAL STANCE INVOLVED EYES OPEN}

DMMLIUSIEC: DYNAMIC MEAN MEDIAL LATERAL INDEX UNILATERAL STANCE INVOLVED EYES CLOSE

The results of paired t-test showed that in the static state, OSI on two legs with open eyes, anterior-posterior stability index (API) on two legs with open eyes, overall stability index on the affected leg with closed eyes and MLI on the affected leg with open and closed eyes (Table 2) showed a significant reduction, and in the dynamic state, the overall stability indices (OSI), the anterior-posterior and lateral indices (API), and ( MLI) on two legs with open and closed eyes, overall and anterior-posterior stability index (OSI) and (API) on the affected leg with closed and open eyes and MLI on the affected leg with open eye also showed a significant reduction $(\mathrm{P}<0.05)$ (Table 3).

In the static state, OSI on two legs with closed eyes, anterior-posterior stability index (API) on two legs with closed eyes, overall stability index on the affected leg with open eyes and MLI on the affected leg with open and closed eyes (Table 2) did not show any significant reduction, and also in the dynamic state, the lateral stability index on the affected leg with closed eyes did not show any reduction $(\mathrm{P}<0.05)$ (Table 3$)$. The mean pain score showed a significant improvement $(\mathrm{P}<0.05)$ (Tables $2 \& 3$ ).

Pearson test results of the variables of static balance indices before and after treatment showed that there was no significant relationship between the static balance and pain severity indices before and after treatment $(\mathrm{P}>0.05)$.

Pearson test results of the variables of dynamic balance indices before and after treatment showed generally that there was no significant relationship between dynamic balance indices and pain severity before treatment $(\mathrm{P}>0.05)$; but there was a significant relationship between dynamic balance indices and pain severity after treatment $(\mathrm{P}<0.05)$. 
There was a significant moderate direct and indirect correlation between dynamic balance indices and pain severity after treatment.

Relation between pain severity and dynamic balance (overall, anterior-posterior, and medial-lateral) indices after treatment shows that there is no correlation between pain severity and dynamic balance indices for overall stability index $(\mathrm{P}>0.05)$. However, there exist a relationship between pain severity and dynamic balance index for the anterior-posterior stability index on the two legs and the affected leg with closed eyes $(\mathrm{P}<0.05)$, as well as a correlation between pain severity and dynamic balance index for the medial-lateral stability index on the two legs with closed eyes $(\mathrm{P}<0 / 05)$.

\section{Discussion}

Significant improvement in pain severity and postural stability indices was reported in patients with knee osteoarthritis after 3 weeks of balance trainings. Also, the results of the correlation study showed that there was no significant relationship between the static balance indices and the severity of pain before and after treatment. On the other hand, there was no significant relationship between dynamic balance indices and pain severity before treatment, but there was a significant relationship between dynamic balance indices and pain severity after treatment. However, it can be said that there is a significant moderate direct and indirect relation between dynamic balance indices and severity of pain after treatment. There was no correlation between pain severity and dynamic balance indices for the overall stability index, but there was a relationship between pain severity and dynamic balance index for the anterior-posterior stability index on two legs and affected leg and the medial-lateral stability index on two legs with closed eyes.

In a study conducted by N. Shakoor et al, they examined the relationship between pain severity and muscle strength and proprioception in patients with knee osteoarthritis through 8 weeks of home trainings; the results of this study were consistent with our one. The home trainings resulted in a significant improvement in muscle pain and strength. Pain may be an indirect factor affecting muscle strength and proprioception in these individuals. In the basis of relationships, an indirect significance was found between the severity of pain and muscle strength and proprioception. After 8 weeks, there was a significant direct correlation between pain severity and muscle strength and proprioception (Shakoor et al., 2008). This suggests that pain may be a factor that affects muscle strength and proprioception, so that pain reduction may improve the voluntary contraction of the maximal muscle, which can improve the function of the individual (Hassan et al., 2002). A study done by MC Hall et al in 2005, they examined the relative effect of radiographic osteoarthritis and pain on quadriceps strength, proprioception, static postural sway, and lower extremity function, which was consistent with our study. Patients with knee pain showed lower strength of quadriceps muscle, greater postural sway and higher disability (Hall et al., 2006). On the other hand, knee osteoarthritis patients reported a higher postural sway than normal people, consequently a weaker balance (Hassan et al., 2001). In addition, the individuals showed greater postural sway when they closed their eyes, but efficiency with open eyes showed greater discrepancy between groups (Hall et al., 2006). The study done by Kyung Kim et al was in line with our study. In this study, the effects of knee extensor muscles strengthening trainings and balance ability through standing trainings on unstable supportive level were evaluated on pain relief in patients with knee osteoarthritis. The results showed that these trainings positively influenced the ability to balance in standing position and subsequently reduced joint pain, which resulted in improved performance (Masui et al., 2006).

In a study done by Ahmed et al, they used strengthening trainings for quadriceps and hamstring muscles (Al-Johani et al., 2014). The results showed that pain reduction objectively increased the range of motion and reduced the functional limitations (Kim et al., 2016). Their research results were similar to our ones, because a gradual increase in loading resulted in a significant reduction in pain after muscular strengthening trainings (Kim et al., 2016). These results showed that both groups of balance and strengthening trainings stimulated proprioception receptors that were effective in increasing knee stability in patients with knee osteoarthritis; it was associated with increased stability in the knee pain reduction. In the study of Hassan et al, it has been reported that people with knee osteoarthritis have more sway in each of the two anterior-posterior and lateral portions than those in the control group. The secondary muscular dysfunction has related to increased pain and excess weight, all of which has led to a reduction in muscle's ability to maintain postural stability (Hassan et al., 2001).

The relationship between pain severity and balance indices can be explained by the following: Pain is a risk factor for the development of radiographic symptoms of knee osteoarthritis (Hochberg, 1996). Electromyographic studies indicate that painful knee osteoarthritis is associated with an increase in quadriceps muscle activity, which is due to the unusual charge of the afferent fibers of the muscle, tendons and joint receptors (Brucini, Duranti, Galletti, Pantaleo, \& Zucchi, 1981). Therefore, people with knee osteoarthritis during walking tend to exhibit greater 
pressure and angular acceleration during sway (Hassan et al., 2002). This problem results from a lack of coordination of the neuromuscular system, which probably predisposes a person to future osteoarthritis (Radin, Yang, Riegger, Kish, \& O'Connor, 1991). Pain severity has been reported as one of the predisposing factors for the changes in postural sway in people with knee osteoarthritis (Hassan et al., 2002). Regarding these, it can be concluded that balance trainings can lead to significant improvement in pain severity and postural stability indices in patients with knee osteoarthritis. However, pain can be considered as an effective factor in evaluating postural stability indices in these patients. In this study, there was a significant relationship between dynamic balance indices and pain severity. These relationships may provide a meaningful insight into the pathophysiology of neuromuscular deficits in knee osteoarthritis patients and require further research. Further studies should be performed on the effect of pain on neuromuscular factors and for determining the relationship between these factors. Future studies also need to consider the role of the ankle joint proprioception and the strength of cuff muscles in balancing patients with knee osteoarthritis.

\subsection{Appreciation}

The authors of this article express their appreciation for the assistance and cooperation of the research deputy of Zahedan University of Medical Sciences in financing the research, the colleagues of the physiotherapy department of Razmjou Moghaddam clinic, as well as all the patients who participated in the project.

\section{References}

Akbari, N. J., Ashtiani, A. R. A., \& Mohammadi, M. (2017). Investigating the impact of balance exercises on balance indices in knee osteoarthritis patients. Pharmacophore, $8(6 \mathrm{~s})$.

Al-Johani, A. H., Kachanathu, S. J., Hafez, A. R., Al-Ahaideb, A., Algarni, A. D., Alroumi, A. M., \& Alenazi, A. M. (2014). Comparative study of hamstring and quadriceps strengthening treatments in the management of knee osteoarthritis. Journal of physical therapy science, 26(6), 817-820.

Ashtiani, A. R. A., Akbari, N. J., Mohammadi, M., \& Nouraisarjou, S. (2018). The Effect of Balance Exercises on Knee Instability and Pain Intensity in Patients with Knee Osteoarthritis: A Randomized Clinical Trial. Journal of Research in Medical and Dental Science, 6(2), 74-82.

Barrett, D., Cobb, A., \& Bentley, G. (1991). Joint proprioception in normal, osteoarthritic and replaced knees. The Journal of bone and joint surgery. British volume, 73(1), 53-56.

Brucini, M., Duranti, R., Galletti, R., Pantaleo, T., \& Zucchi, P. L. (1981). Pain thresholds and electromyographic features of periarticular muscles in patients with osteoarthritis of the knee. Pain, 10(1), 57-66.

Chaipinyo, K., \& Karoonsupcharoen, O. (2009). No difference between home-based strength training and homebased balance training on pain in patients with knee osteoarthritis: a randomised trial. Australian Journal of Physiotherapy, 55(1), 25-30.

Davis, M., Ettinger, W., Neuhaus, J., \& Mallon, K. (1991). Knee osteoarthritis and physical functioning: evidence from the NHANES I Epidemiologic Followup Study. The Journal of rheumatology, 18(4), 591-598.

Duman, I., Taskaynatan, M. A., Mohur, H., \& Tan, A. K. (2012). Assessment of the impact of proprioceptive exercises on balance and proprioception in patients with advanced knee osteoarthritis. Rheumatology international, 32(12), 3793-3798.

Ezadpanah, A., Moazami, M., \& Khoshraftar Yazdi, N. (2016). Effect of a period of therapeutic exercise and detraining after that on balance in the women with knee osteoarthritis. Journal of Modern Rehabilitation, 9(5), 101-109.

Hall, M. C., Mockett, S. P., \& Doherty, M. (2006). Relative impact of radiographic osteoarthritis and pain on quadriceps strength, proprioception, static postural sway and lower limb function. Annals of the rheumatic diseases, 65(7), 865-870.

Hassan, B., Doherty, S., Mockett, S., \& Doherty, M. (2002). Effect of pain reduction on postural sway, proprioception, and quadriceps strength in subjects with knee osteoarthritis. Annals of the rheumatic diseases, 61(5), 422-428.

Hassan, B., Mockett, S., \& Doherty, M. (2001). Static postural sway, proprioception, and maximal voluntary quadriceps contraction in patients with knee osteoarthritis and normal control subjects. Annals of the rheumatic diseases, 60(6), 612-618.

Hochberg, M. (1996). Development and progression of osteoarthritis. The Journal of rheumatology, 23(9), 14971949. 
Jan, M.-H., Lin, C.-H., Lin, Y.-F., Lin, J.-J., \& Lin, D.-H. (2009). Effects of weight-bearing versus nonweightbearing exercise on function, walking speed, and position sense in participants with knee osteoarthritis: a randomized controlled trial. Archives of physical medicine and rehabilitation, 90(6), 897-904.

Kavounoudias, A., Gilhodes, J.-C., Roll, R., \& Roll, J.-P. (1999). From balance regulation to body orientation: two goals for muscle proprioceptive information processing? Experimental Brain Research, 124(1), 80-88.

Kim, K., Lee, H.-Y., \& Lim, S.-J. (2016). Effects of increased standing balance on pain in patients with knee osteoarthritis. Journal of physical therapy science, 28(1), 87-89.

Lyytinen, T., Liikavainio, T., Bragge, T., Hakkarainen, M., Karjalainen, P. A., \& Arokoski, J. P. (2010). Postural control and thigh muscle activity in men with knee osteoarthritis. Journal of Electromyography and Kinesiology, 20(6), 1066-1074.

Masui, T., Hasegawa, Y., Yamaguchi, J., Kanoh, T., Ishiguro, N., \& Suzuki, S. (2006). Increasing postural sway in rural-community-dwelling elderly persons with knee osteoarthritis. Journal of Orthopaedic Science, 11(4), 353.

McCarthy, C., Mills, P., Pullen, R., Richardson, G., Hawkins, N., Roberts, C., . . . Oldham, J. (2004). Supplementation of a home-based exercise programme with a class-based programme for people with osteoarthritis of the knees: a randomised controlled trial and health economic analysis. Health technology assessment (Winchester, England), 8(46), iii-iv, 1-61.

Messier, S. P., Royer, T. D., Craven, T. E., O'toole, M. L., Burns, R., \& Ettinger, W. H. (2000). Long-term exercise and its effect on balance in older, osteoarthritic adults: results from the Fitness, Arthritis, and Seniors Trial (FAST). Journal of the American Geriatrics Society, 48(2), 131-138.

Moskowitz, R. (1992). Experimental models of osteoarthritis. Osteoarthritis: diagnosis and medical/surgical management, 213-232.

Odding, E., Valkenburg, H. A., Algra, D., Vandenouweland, F. A., Grobbee, D. E., \& Hofman, A. (1998). Associations of radiological osteoarthritis of the hip and knee with locomotor disability in the Rotterdam Study. Annals of the rheumatic diseases, 57(4), 203-208.

Peat, G., McCarney, R., \& Croft, P. (2001). Knee pain and osteoarthritis in older adults: a review of community burden and current use of primary health care. Annals of the rheumatic diseases, 60(2), 91-97.

Perlau, R., Frank, C., \& Fick, G. (1995). The effect of elastic bandages on human knee proprioception in the uninjured population. The American journal of sports medicine, 23(2), 251-255.

Radin, E. L., Yang, K. H., Riegger, C., Kish, V. L., \& O'Connor, J. J. (1991). Relationship between lower limb dynamics and knee joint pain. Journal of orthopaedic research, 9(3), 398-405.

Rätsepsoo, M., Gapeyeva, H., Sokk, J., Ereline, J., Haviko, T., \& Päsuke, M. (2013). Leg extensor muscle strength, postural stability, and fear of falling after a 2-month home exercise program in women with severe knee joint osteoarthritis. Medicina, 49(8), 54.

Shakoor, N., Furmanov, S., Nelson, D., Li, Y., \& Block, J. (2008). Pain and its relationship with muscle strength and proprioception in knee OA: results of an 8-week home exercise pilot study. $J$ Musculoskelet Neuronal Interact, 8(1), 35-42.

\section{Copyrights}

Copyright for this article is retained by the author(s), with first publication rights granted to the journal.

This is an open-access article distributed under the terms and conditions of the Creative Commons Attribution license (http://creativecommons.org/licenses/by/4.0/). 